\title{
Campylobacteriosis Outbreak Associated with Contaminated Municipal Water Supply — Nebraska, 2017
}

\author{
Caitlin Pedati, MD ${ }^{1}$; Samir Koirala, MBBS ${ }^{1,2}$; Tom Safranek, MD ${ }^{1}$; Bryan F. Buss, DVM ${ }^{1,2}$; Anna V. Carlson, PhD ${ }^{1}$
}

In March 2017, the Nebraska Department of Health and Human Services (NDHHS) and the Southwest Nebraska Public Health Department were notified of an apparent cluster of Campylobacter jejuni infections in city $\mathrm{A}$ and initiated an investigation. Overall, 39 cases were investigated, including six confirmed and 33 probable. Untreated, unboiled city A tap water (i.e., well water) was the only exposure significantly associated with illness (odds ratio $[\mathrm{OR}]=7.84$; 95\% confidence interval $[\mathrm{CI}]=1.69-36.36$ ). City $\mathrm{A}$ is served by four untreated wells and an interconnected distribution system. Onsite investigations identified that a center pivot irrigation system intended to pump livestock wastewater from a nearby concentrated animal feeding operation onto adjacent farmland had malfunctioned, allowing excessive runoff to collect in a road ditch near two wells that supplied water to the city. These wells were promptly removed from service, after which no subsequent cases occurred. This coordinated response rapidly identified an important risk to city A's municipal water supply and provided the evidence needed to decommission the affected wells, with plans to build a new well to safely serve this community.

\section{Investigation and Results}

On March 10, 2017, NDHHS was notified of five reports of campylobacteriosis in the Southwest Nebraska Public Health Department jurisdiction. Two positive culture reports and three positive culture-independent diagnostic tests, specifically a gastrointestinal polymerase chain reaction (PCR) panel, were received from persons not living together. Campylobacteriosis is a reportable condition in Nebraska, and this number of cases was higher than expected; during 2006-2016, an average of one Campylobacter case was reported in a city A resident every 3 years. Initial questioning of ill persons did not include an assessment of exposure to untreated drinking water and suggested ground beef consumption as a possible shared exposure. The Nebraska Department of Agriculture Food Safety and Consumer Protection obtained distribution records for poultry and ground beef for two local restaurants and one local grocery store. The distribution of poultry and ground beef was evaluated by reviewing the routing records of these products to their source, and no evidence of a shared poultry source was identified. The ground beef was not ground in-house at the grocery store, and the distributors that supplied ground beef to the grocery store and each of the two local restaurants were not shared. Through interviews of city A residents and

\section{INSIDE}

174 Public Health Emergency Risk Communication and Social Media Reactions to an Errant Warning of a Ballistic Missile Threat — Hawaii, January 2018

177 Leveraging Existing Birth Defects Surveillance Infrastructure to Build Neonatal Abstinence Syndrome Surveillance Systems - Illinois, New Mexico, and Vermont, 2015-2016

181 Notes from the Field: Lead and Cadmium Exposure in Electronic Recyclers - Two States, 2015 and 2017

183 Notes from the Field: Enteroinvasive Escherichia coli Outbreak Associated with a Potluck Party — North Carolina, June-July 2018

185 Notes from the Field: Human Brucella abortus RB51 Infections Caused by Consumption of Unpasteurized Domestic Dairy Products — United States, 2017-2019

187 QuickStats

Continuing Education examination available at https://www.cdc.gov/mmwr/cme/conted_info.html\#weekly.

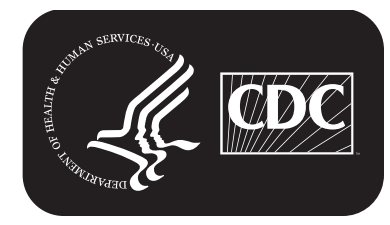

U.S. Department of Health and Human Services Centers for Disease Control and Prevention 
business owners, investigators were made aware of a report of standing water that "smelled of cattle manure" in a roadside ditch near two municipal water wells.

A collaborative on-site investigation revealed that during the pumping of a large volume of livestock wastewater from a concentrated animal feeding operation through a center pivot irrigation system, the system malfunctioned at an undetermined time. The wastewater was intended to be placed on adjacent farmland. This malfunction allowed excessive runoff to flood a road ditch approximately 15 feet $(4.6 \mathrm{~m})$ from two municipal water well houses $(3$ and 4$)$ that had been operating 6 days before the onset of illness in the first patient. The presence of this standing water was confirmed by city A water operators, who reported seeing water in the ditch for 4 days (February 22-25) (Figure). Pump records indicated that during February 22-27, well 3 was in use, and during February 28-March 7, well 4 was in use (Table 1). During both periods, another well (well 2) was also operating. Wells are rotated in and out of service by city operators as part of regular operations. Water is distributed through the well system without any disinfection or filtration. Routine total coliform and Escherichia coli testing of water from the distribution system was performed on March 8; however, only wells 2 and 5 were operating on that date. As part of the investigation, additional coliform and E. coli testing was performed again on March 16 on direct samples from wells 2, 3, 4, and 5; bacterial culture specifically for Campylobacter was performed on March 20 (wells 4 and 5) and 27 (wells 2 and 3). All samples were negative for coliforms and Campylobacter. No additional pump or testing records were reviewed.

On March 16, Nebraska Department of Environmental Quality and the Department of Agriculture conducted an additional investigation of two concentrated animal feeding operation-certified waste lagoons (a manufactured basin that collects livestock waste and water in an oxygen-deprived setting to promote anaerobic conditions as a way to manage refuse)* and associated use of three pivot irrigation systems. The investigation team observed that water from the waste lagoons had been pumped through a pivot onto an adjacent field, which is a common farming practice for fertilizing farm ground or watering crops. City operators confirmed that on February 24 they had observed flow of livestock wastewater into the road ditch near well 4 . They followed the wastewater up the road ditch and reported that it came out of the farmland upstream from the wells. Investigators also obtained details of total well depths, static water levels, and pumping water levels (measured during active pumping). Wells 4 and 3 were relatively shallow, with static water levels of 21 and 22 feet, pumping levels of 25 and 26 feet, and total well depths of 43 and 46 feet, respectively; both began service in the 1930s, similar to the other wells in the system, which were also older.

While details around this event were being clarified and environmental testing was pending, an Internet-based questionnaire was designed to aid case-finding and assess potential

*https://www3.epa.gov/npdes/pubs/alagoons.pdf.

The MMWR series of publications is published by the Center for Surveillance, Epidemiology, and Laboratory Services, Centers for Disease Control and Prevention (CDC), U.S. Department of Health and Human Services, Atlanta, GA 30329-4027.

Suggested citation: [Author names; first three, then et al., if more than six.] [Report title]. MMWR Morb Mortal Wkly Rep 2019;68:[inclusive page numbers].

\section{Centers for Disease Control and Prevention \\ Robert R. Redfield, MD, Director \\ Anne Schuchat, MD, Principal Deputy Director \\ Leslie Dauphin, PhD, Acting Associate Director for Science \\ Barbara Ellis, PhD, MS, Acting Director, Office of Science Quality \\ Chesley L. Richards, MD, MPH, Deputy Director for Public Health Scientific Services \\ Michael F. Iademarco, MD, MPH, Director, Center for Surveillance, Epidemiology, and Laboratory Services}

MMWR Editorial and Production Staff (Weekly)
Martha F. Boyd, Lead Visual Information Specialist Maureen A. Leahy, Julia C. Martinroe, Stephen R. Spriggs, Tong Yang, Visual Information Specialists

Quang M. Doan, MBA, Phyllis H. King,

Terraye M. Starr, Moua Yang,

Information Technology Specialists
MMWR Editorial Board Timothy F. Jones, MD, Chairman Robin Ikeda, MD, MPH

Matthew L. Boulton, MD, MPH Virginia A. Caine, MD

Katherine Lyon Daniel, PhD

Jonathan E. Fielding, MD, MPH, MBA

David W. Fleming, MD

William E. Halperin, MD, DrPH, MPH
Jewel Mullen, MD, MPH, MPA

Jeff Niederdeppe, $\mathrm{PhD}$

Patricia Quinlisk, MD, MPH
Phyllis Meadows, PhD, MSN, RN
Stephen C. Redd, MD

Patrick L. Remington, MD, MPH

Carlos Roig, MS, MA

William Schaffner, MD

Morgan Bobb Swanson, BS 
exposures. A probable case was defined as a diarrheal illness of $\geq 2$ days' duration with one or more additional signs or symptoms (nausea, vomiting, fever, chills, or headache) in a city A resident, with onset during February 28-March 23, 2017. A confirmed case was defined as a person meeting the probable case definition with either stool culture or PCR-positive results for Campylobacter, or a laboratory-confirmed probable illness in a nonresident who worked, dined, or shopped for groceries in city A. Among approximately 600 city A residents, 94 (16\%) completed a questionnaire to report food consumption history, drinking water source, animal exposures, and symptoms. Among questionnaire respondents, 39 (41\%) campylobacteriosis cases (six confirmed and 33 probable) were identified, with illness onset from February 28-March 21 (Figure); 25 (64\%) cases occurred in females and $14(36 \%)$ in males. The median age was 34.5 years (range $=1.5-85$ years). Twelve $(31 \%)$ patients sought medical care, and three (8\%) were hospitalized; no deaths were reported.

Data analysis indicated a significant association between ill persons and consumption of untreated, unboiled municipal tap water $(\mathrm{OR}=7.84 ; 95 \% \mathrm{CI}=1.69-36.36)$ (Table 2). Other exposures were assessed, including unpasteurized milk, animal contact, raw poultry, and ground beef, but none demonstrated a significant association with illness. Notably, no cases were reported among the approximately 28 residents of city A's

\section{Summary}

What is already known about this topic?

Campylobacter has been implicated in outbreaks associated with poultry products, unpasteurized milk, and contaminated water sources.

What is added by this report?

A center pivot irrigation system intended to pump livestock waste water onto adjacent farmland in Nebraska malfunctioned, allowing excessive run off to collect in a road ditch near two wells that fed a municipal water supply, sickening 39 persons who consumed untreated city water. The use of culture-independent diagnostic tests facilitated case identification allowing for rapid public health response.

What are the implications for public health practice?

Access to clean water sources continues to be an important public health issue, and public health professionals should consider exposure to untreated water sources as a potential cause for Campylobacter outbreaks.

only nursing home, which used city water but treated it with a reverse osmosis system.

\section{Public Health Response}

Wells 3 and 4 were both permanently removed from service on March 16, and no additional illnesses were reported with

FIGURE. Confirmed $(n=6)$ and probable $(n=33)$ campylobacteriosis cases, by date of illness onset and well pumping date - Nebraska, 2017

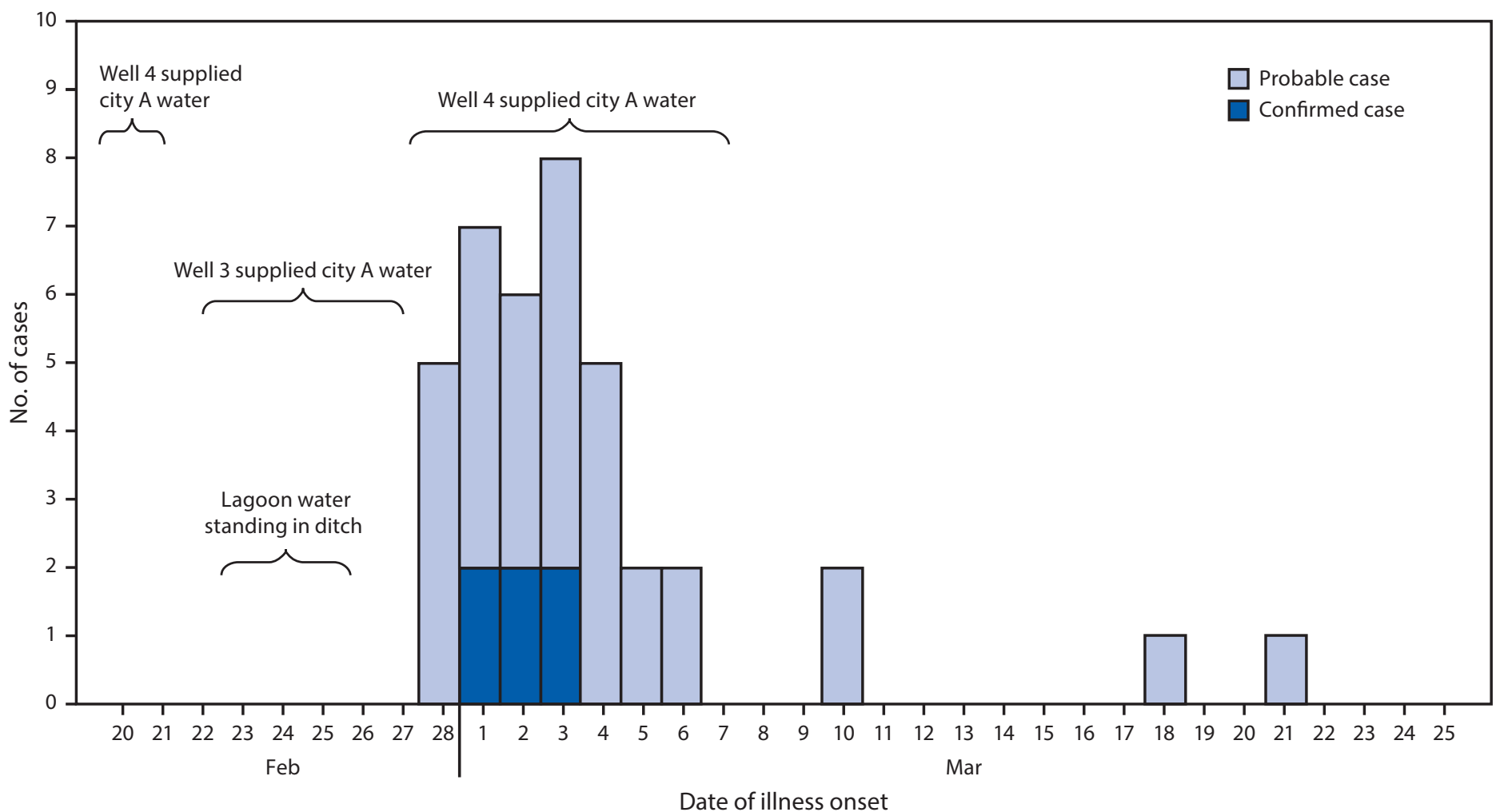


Morbidity and Mortality Weekly Report

TABLE 1. Volume* and percentage of water pumped from each city A well, by week — Nebraska, 2017

\begin{tabular}{|c|c|c|c|c|c|}
\hline \multirow[b]{2}{*}{ Dates } & \multicolumn{4}{|c|}{ Volume (\%) } & \multirow[b]{2}{*}{ Total volume } \\
\hline & Well 2 & Well $3^{+}$ & Well $4^{\dagger}$ & Well 5 & \\
\hline February 15-21, 2017 & $278(40.0)$ & $0(0)$ & $417(60.0)$ & $0(0)$ & 695 \\
\hline February 22-27, 2017 & $282(48.8)$ & $296(51.2)$ & $0(0)$ & $0(0)$ & 578 \\
\hline February 28-March 7, 2017 & $327(40.0)$ & $0(0)$ & $491(60.0)$ & $0(0)$ & 818 \\
\hline March 8-13, 2017 & $207(32.7)$ & $0(0)$ & $0(0)$ & $426(67.3)$ & 633 \\
\hline
\end{tabular}

* $x 1,000$ gallons.

† Well 3 and well 4 were adjacent to the ditch flooded by livestock wastewater (February 22-25).

TABLE 2. Potential exposures reported by survey respondents included for analysis $(n=94)$ in a community-wide campylobacteriosis investigation and corresponding odds ratios - city A, Nebraska, February 23-March 9, 2017

\begin{tabular}{|c|c|c|c|c|c|}
\hline \multirow[b]{3}{*}{ Exposure } & \multicolumn{4}{|c|}{ No. (\%) } & \multirow[b]{3}{*}{ OR $(95 \% \mathrm{Cl})^{*}$} \\
\hline & \multicolumn{2}{|c|}{ Cases $(n=38)$} & \multicolumn{2}{|c|}{ Controls $(n=56)$} & \\
\hline & Exposed & Not exposed & Exposed & Not exposed & \\
\hline City tap water & $36(94.7)$ & $2(5.3)$ & 39 (69.6) & $17(30.4)$ & $7.84(1.69-36.36)$ \\
\hline Unpasteurized milk & $0(0)$ & $38(100)$ & $0(0)$ & $56(100)$ & Undefined \\
\hline Any chicken & $12(33.3)$ & $24(66.7)$ & $24(42.8)$ & $32(57.1)$ & $0.66(0.27-1.59)$ \\
\hline Ground beef & $24(66.7)$ & $12(33.3)$ & $33(62.3)$ & $20(37.7)$ & $1.21(0.49-2.94)$ \\
\hline Animal contact & $19(51.4)$ & $18(48.7)$ & 40 (72.7) & $15(27.3)$ & $0.39(0.16-0.95)$ \\
\hline
\end{tabular}

Abbreviations: $\mathrm{Cl}=$ confidence interval; $\mathrm{OR}=$ odds ratio.

onset after March 21. On April 25, NDHHS reclassified these wells to Emergency Status, meaning the well can only be pumped during a case of emergency (e.g., fire, drought, etc.) for nonpotable purposes. Furthermore, meetings were held with area stakeholders to present these findings as evidence to support the award of a planning grant to city A to explore options for a new, higher-volume well to be dug to an acceptable depth in a different location.

\section{Discussion}

This investigation implicates Campylobacter jejuni as the cause of this outbreak, most likely from a municipal water system contaminated by wastewater runoff from an adjacent concentrated animal feeding operation (1). In addition to environmental and statistical findings, this conclusion is consistent with prior investigations that demonstrate Campylobacter outbreaks of similar size are historically associated with contaminated water $(2-7)$. Although laboratory testing of the water in this investigation did not yield any positive results, samples were not taken until long after the contamination event, and test results might have been affected by switches among wells supplying the system over time. These findings also suggest that routine coliform testing might not be a good indicator of the presence of Campylobacter species (8). Further, it is possible that Campylobacter in particular might be viable but not necessarily detectable by culture in water systems $(9,10)$. The use of both culture and culture-independent diagnostic tests (PCR) were needed to detect the initial cluster of cases and early recognition of this outbreak. If culture alone had been used, only two cases would have been reported, one of which did not occur in a city A resident. Of those two culture-confirmed cases, one patient refused the interview and the other had typical Campylobacter exposures, such as live poultry, which might not have prompted such a rapid response. This investigation demonstrates the importance of considering exposure to untreated water sources as a potential cause for Campylobacter outbreaks. Including this risk factor in initial questioning could help to expedite outbreak investigations. Ultimately, early recognition and a coordinated response by several state and local agencies greatly facilitated this successful public health intervention.

\section{Acknowledgments}

Southwest Nebraska Public Health Department; Nebraska Department of Environmental Quality; Nebraska Department of Agriculture.

Corresponding author: Caitlin Pedati, Caitlin.Pedati@idph.iowa.gov.

${ }^{1}$ Nebraska Department of Health and Human Services, Lincoln, Nebraska; ${ }^{2}$ Division of State and Local Readiness, Office of Public Health Preparedness and Response, CDC.

All authors have completed and submitted the ICMJE form for disclosure of potential conflicts of interest. No potential conflicts of interest were disclosed.

\section{References}

1. CDC. Campylobacter and drinking water from private wells. Atlanta, GA: US Department Health and Human Services, CDC; 2015. https:// www.cdc.gov/healthywater/drinking/private/wells/disease/ campylobacter.html

2. Ball A. Estimation of the burden of water-borne disease in New Zealand: preliminary report. Wellington, New Zealand: Ministry of Health; 2006. https://www.health.govt.nz/system/files/documents/publications/waterborne-disease-burden-prelim-report-feb07-v2.pdff 
3. Clark CG, Price L, Ahmed R, et al. Characterization of waterborne outbreak-associated Campylobacter jejuni, Walkerton, Ontario. Emerg Infect Dis 2003;9:1232-41. https://doi.org/10.3201/eid0910.020584

4. DeFraites RF, Sanchez JL, Brandt CA, et al. An outbreak of Campylobacter enteritis associated with a community water supply on a U.S. military installation. MSMR 2014;21:10-5.

5. Jakopanec I, Borgen K, Vold L, et al. A large waterborne outbreak of campylobacteriosis in Norway: the need to focus on distribution system safety. BMC Infect Dis 2008;8:128. https://doi. org/10.1186/1471-2334-8-128

6. Richardson G, Thomas DR, Smith RMM, et al. A community outbreak of Campylobacter jejuni infection from a chlorinated public water supply. Epidemiol Infect 2007;135:1151-8. https://doi.org/10.1017/ S0950268807007960
7. Tauxe RV. Epidemiology of Campylobacter jejuni infections in the United States and other industrialized nations. In: Nachamkin I, Tomkins S, Blaser M, eds. Campylobacter jejuni: current status and future trends. Washington, DC: American Society for Microbiology; 1992:9-19.

8. St-Pierre K, Lévesque S, Frost E, Carrier N, Arbeit RD, Michaud S. Thermotolerant coliforms are not a good surrogate for Campylobacter spp. in environmental water. Appl Environ Microbiol 2009;75:6736-44. https://doi.org/10.1128/AEM.00486-09

9. Jones DM, Sutcliffe EM, Curry A. Recovery of viable but non-culturable Campylobacter jejuni. J Gen Microbiol 1991;137:2477-82. https://doi. org/10.1099/00221287-137-10-2477

10. Rollins DM, Colwell RR. Viable but nonculturable stage of Campylobacter jejuni and its role in survival in the natural aquatic environment. Appl Environ Microbiol 1986;52:531-8. 